\title{
A utilização da pesquisa de informações básicas municipais (MUNIC) e da pesquisa de informações básicas estaduais (ESTADIC) como instrumento de acompanhamento e monitoramento de políticas públicas
}

Vânia Maria Pacheco ${ }^{1}$

1 Gerente da pesquisa de informações básicas municipais, MUNIC - IBGE

\section{Introdução}

Procurando atender à demanda por informações municipais e estaduais de forma periódica, o Instituto Brasileiro de Geografia e Estatística (IBGE) realiza anualmente a Pesquisa de Informações Básicas Municipais (MUNIC) e a Pesquisa de Informações Básicas Estaduais (ESTADIC).

Tanto a MUNIC quanto a ESTADIC tratam da gestão pública municipal e estadual efetuando um levantamento pormenorizado de informações sobre a estrutura, a dinâmica e o funcionamento das instituições públicas municipais e estaduais, em especial a prefeitura e o governo do estado, com- preendendo, também, diferentes políticas e setores que envolvem estas instâncias de governo. 0 objeto de interesse da MUNIC é a gestão dos 5.570 municípios do país e da ESTADIC a gestão das 27 Unidades da Federação.

A unidade de investigação da MUNIC é o município, da ESTADIC o estado e o Distrito Federal, sendo informante principal a prefeitura e o governo estadual e distrital mediante os diversos setores que os compõem; as instituições ligadas a outros poderes públicos locais ou instaladas localmente constituem unidades secundárias de informação. Assim, as in- 
formações coletadas em cada município ou estado são resultado de entrevistas aplicadas aos gestores, posicionados nas diversas áreas e/ou instituições investigados, que detêm informações sobre os órgãos públicos e demais equipamentos municipais, estaduais e distrital.

A coleta dos dados é realizada após treinamento centralizado, em que estão presentes supervisores regionais e técnicos de todas as Unidades Estaduais. Posteriormente, estes são responsáveis pelo treinamento dos técnicos das mais de 500 agências do IBGE no país.

Os supervisores estaduais são os responsáveis pela coleta das informações. A fim de efetuar a coleta das informações da MUNIC, o pesquisador do IBGE faz um primeiro contato com a prefeitura de cada município a seu encargo, no caso da ESTADIC, o supervisor entra em contato com o governo do estado ou distrital, com objetivo de apresentar as pesquisas ao prefeito e ao governador e obter a indicação de pessoas na administração municipal, estadual e distrital com capacidade de responder sobre os temas investigados. Esta pessoa é entrevistada, sempre que possível, e deve manter contato com o pesquisador quando houver a necessidade de esclarecer algum item, procedimento ou conceito relativo à pesquisa. Para possibilitar o preenchimento dos questionários pelos diversos segmentos das prefeituras, governos estaduais e distrital, cada instrumento de coleta apresenta as explicações dos termos e conceitos utilizados mais importantes dispostos com os quesitos correlatos.

Um importante aspecto a ser destacado quanto à metodologia interna dos questionários refere-se ao formato de determinação do informante na prefeitura e no governo estadual. Com o firme propósito de qualificá-lo, pessoal e profissionalmente, bem como ampliar seu comprometimento com a qualidade das respostas fornecidas, procede-se à sua identificação em cada um dos blocos temáticos específicos. 
Os temas e questões abordados na pesquisa visam dar resposta às necessidades de informação da sociedade e dos estados brasileiros. Para tanto, a Munic MUNIC e a Estadic ESTADIC têm por objetivo propiciar a construção de um amplo perfil da administração pública dos municípios e das unidades da federação e a consolidação de uma base municipal, estadual e distrital de informações com dados estatísticos atualizados e indicadores relevantes para avaliação e monitoramento do quadro institucional e do desenvolvimento das cidades e estados do Brasil. Na elaboração dos instrumentos de coleta, a pesquisa é receptiva à introdução de novos quesitos, temas ou suplementos que forneçam aos órgãos governamentais, setores privados e a sociedade civil subsídios para o conhecimento da realidade institucional, o planejamento e a tomada de decisão.

\section{As pesquisas}

A produção de informações e estudos municipais pelo IBGE remonta a meados da década de 1950, com a elaboração da Enciclopédia dos Municípios Brasileiros pelos Conselhos Nacionais de Geografia e Estatística, divulgada por essa instituição entre 1957 e 1964.

O primeiro levantamento de Informações Básicas Municipais, lançado em agosto de 1961, originou-se da demanda por informações municipais por usuários do governo, empresas privadas e universidades, dentre outros. Isto permitiu um conhecimento mais abrangente de aspectos físicos, demográficos, econômicos, sociais e culturais dos municípios brasileiros, e teve periodicidade anual regular até 1974, voltando a ser divulgada em 1982 e interrompida no início da década de 1990.

Desde a Constituição de 1988, a necessidade de se aprofundar o conhecimento sobre a realidade municipal vem se ampliando. A escala local vem adquirindo uma importância cada vez maior no processo de formulação e implementação de políticas públicas, como parte de um processo amplo e crescente de descentralização governamental, em que maiores atribuições e responsabilidades têm sido repassadas para os municípios, na prestação de serviços públicos à 
população. Neste contexto, diversos órgãos públicos federais e regionais têm organizado e disponibilizado registros administrativos para informação geral e, principalmente, para subsidiar a elaboração de políticas sociais, o planejamento e o acompanhamento de programas mediante elaboração de indicadores no âmbito municipal.

A concepção da Pesquisa de Informações Básicas Municipais surgiu no bojo deste processo. Este levantamento relativo às prefeituras contou inicialmente, em 1998, com uma pesquisa-piloto no Estado do Rio de Janeiro, a fim de avaliar a operação e os instrumentos de coleta das informações e definir as estratégias para sua implantação no restante do país, iniciando em 1999 com abrangência nacional e periodicidade anual. A partir daí, a Pesquisa de Informações Básicas Municipais conserva inalterados três traços fundamentais: a especialização na coleta de dados sobre o poder público municipal, o cunho censitário, a natureza pública das informações reunidas e a obtenção de informações municipais fora da esfera do setor público executivo mas de seu próprio conhecimento.
A MUNIC foi criada com o objetivo de suprir as demandas por informações desagregadas, em nível municipal, sobre a administração pública local, que pudessem contribuir para seu conhecimento, auxiliando o planejamento e aprimoramento da gestão dos municípios.

As informações coletadas pela pesquisa têm se mostrado de extrema utilidade para os gestores e estudiosos do poder local. Possuir dados estatísticos sobre a oferta, a diversidade e a qualidade dos serviços públicos é essencial para aprimorar a capacidade dos governos municipais de atender a população. O conhecimento e aprendizagem sobre a escala local, proporcionados pelas informações estatísticas, vêm responder às exigências imediatas de compreensão da heterogeneidade estrutural do País, a fim de tornar efetiva a imensa riqueza, complexidade e criatividade brasileira no avanço social, político e econômico.

As diversidades produtivas, sociais, culturais e espaciais foram por muito tempo tratadas como desequilíbrios, assimetrias, obstáculos colocados como desafio na 
promoção do desenvolvimento em um país de dimensão continental. O Brasil é um país desigual em muitos aspectos e, neste sentido, o levantamento de registros administrativos fornece informações municipais essenciais para o planejamento, diagnóstico e monitoramento das condições locais.

A Pesquisa de Informações Básicas Municipais, restringindo-se às políticas setoriais relativas apenas à esfera municipal, sobre as quais não há informações em outras fontes, constituiu-se como instrumento para a informação geral e, principalmente, para a elaboração, o planejamento, o acompanhamento e o monitoramento de políticas públicas.

Ao longo das suas onze edições, a MUNIC manteve o foco na estrutura, dinâmica e funcionamento das prefeituras e nos aspectos relativos às condições das cidades e do desenvolvimento urbano sob a circunscrição do poder local, investigando uma grande diversidade de temas relativos ao aparato político-institucional, o planejamento público, os programas sociais, as políticas setoriais, a oferta de serviços e de infraestrutura urbana.
Acompanhando a trajetória da MUNIC, pela primeira vez, em 2012, foi iniciado o levantamento da Pesquisa de Informações Básicas Estaduais - ESTADIC, com o propósito de suprir a lacuna de estudos que focalizam as esferas estaduais, notadamente no que diz respeito às suas administrações, e oferecer elementos para análises sobre como são organizadas administrativamente as Unidades da Federação e como são definidas e implementadas suas políticas públicas.

A construção deste perfil das Unidades da Federação, a partir dos registros e das informações fornecidos pelas administrações públicas, amplia e atualiza o esforço analítico e empírico do Instituto na consolidação de um sistema avançado de informações sobre governos, descentralização, federalismo, gestão e políticas públicas no Brasil.

Em face da diversidade de conteúdos e lógicas adotada por governantes e legisladores estaduais e distritais, bem como da diferença de recursos humanos, financeiros e materiais, de instrumentos legais e mecanismos institucionais, é justo supor que a Pesquisa de Informações Básicas Estaduais abrirá caminho e estimulará os estudos so- 
bre a complexa realidade dessas Unidades da Federação. Em que pese os estados e as gestões estaduais assumirem papel de destaque no cenário político-administrativo nacional, trata-se de universos ainda pouco explorados, uma vez que grande parte dos esforços de pesquisa tem se concentrado na esfera nacional ou na municipal.

Mesmo com a redemocratização e a promulgação da Constituição Federal do Brasil de 1988, quando foi dado maior poder aos municípios, o papel das esferas estaduais manteve a sua importância e visibilidade. Decorridas mais de duas décadas da instalação de um novo formato para o federalismo brasileiro, ainda sabe-se pouco sobre como os governos e as instituições estaduais estão desempenhando seu papel no regime democrático do País à luz da descentralização, e por que os estados eventualmente apresentam padrões de gestão tão diversos nesses processos.

Nesse sentido, a ESTADIC visa oferecer elementos para a análise de questões fundamentais sobre como são governados os estados no Brasil e como políticas públicas são definidas e implementadas nos estados. Sabe-se que a política estadual e suas políticas públicas não são meras reproduções do que ocorre na esfera nacional, mas que se baseiam em programas e práticas próprias e específicas, obtendo diferentes resultados, apesar de ambas as esferas políticas serem regidas por regras relativamente homogêneas.

Com abrangência nacional e periodicidade anual, os dados estatísticos da ESTADIC servem ao planejamento e monitoramento de políticas setoriais, avaliação da performance atual dos estados e análise dos arranjos intergovernamentais, formatos institucionais e padrões das gestões públicas estaduais. O conhecimento e a aprendizagem que proporcionam essas informações estatísticas vêm responder às exigências imediatas de compreensão das mudanças que tenderam a fortalecer as esferas subnacionais de governo, a partir do ciclo de reformas descentralizadoras e do aumento da participação política dos diferentes setores da sociedade organizada.

O número reduzido de unidades de pesquisa permite individualizar as informações obtidas, sendo este um aspecto desejável em investigações que fazem 
uso de registros públicos. Por outro lado, a natureza complexa das administrações estaduais se reflete em diferenças na qualidade e disponibilidade dos registros e informações. Atualmente, contudo, é desejável que as escalas nacional, estadual e local mostrem-se crescentemente articuladas e demonstrem a urgência que têm em engendrar ações mais ágeis, potentes e sistemáticas, o que passa necessariamente pela oferta de informações estatísticas de qualidade, como instrumento efetivo de planejamento, diagnóstico e monitoramento das gestões públicas.

Considerando-se a experiência brasileira no sentido dos avanços social, político e econômico, é de suma importância a obtenção de dados estatísticos com base estadual que expressem de forma clara e objetiva a oferta e a qualidade dos serviços públicos e a capacidade dos gestores estaduais de atender suas populações. O diagnóstico preciso do perfil dos estados brasileiros é um ponto fundamental para que sejam esperadas ações personalizadas, delimitadas pelas políticas nacionais e estaduais, a partir do mapeamento da administração pública enquanto insumo que auxilia tanto os gestores, no planejamento, monitoramento e avaliação de políticas públicas, quanto o cidadão, que passa a entender como estão estruturadas as ações, serviços, projetos e programas no nível estadual. Por gestão dos estados e do Distrito Federal pode-se dizer que perpassam discussões a respeito da organização, quadro funcional, recursos institucionais, políticas de planejamento, programas e ações públicas dos governos estaduais.

As pesquisas permitem retratar o grau de participação e controle popular da ação pública por meio do levantamento de conselhos, comissões e comitês de diversas políticas, e caracterizar o estágio de desenvolvimento institucional das atividades de planejamento e gestão municipal e estadual.

Desde seu lançamento, a MUNIC tem um baixíssimo índice de não resposta e a ESTADIC, nestes 3 anos de existência, não obteve nenhuma recusa de informação. É 
necessário ressaltar que, ao contrário das demais pesquisas efetuadas pelo IBGE, as informações prestadas pelas prefeituras e governos estaduais são de natureza pública, configurando um conjunto de informações divulgadas individualmente.

\section{Monitoramento e avaliação}

A produção de indicadores que se destinam às atividades de monitoramento e avaliação de políticas, programas, ações e projetos é um dos principais desafios da gestão pública envolvida com resultados.

De acordo com a definição da Organização para Cooperação e Desenvolvimento Econômico (OCDE), o monitoramento é um processo contínuo de coleta de informações que utiliza de indicadores previamente definidos com a finalidade de fornecer informações sobre o progresso e o alcance dos objetivos (OCDE, 2002). Para Garcia (2001, p. 29), o monitoramento é "um processo sistemático e contínuo que, produzindo informações sintéticas e em tempo eficaz, permite a rápida avalia- ção situacional e a intervenção oportuna que confirma ou corrige as ações monitoradas".

Já a avaliação é definida por Weiss (1998) como a atividade em que se busca aferir as operações ou resultados de um programa ou política, comparando-as a um conjunto de padrões (explícitos ou implícitos) previamente definidos, com vistas a contribuir para o seu aperfeiçoamento.

Wholey et al. (2004) ressaltam ainda o caráter de aprendizado das avaliações que, segundo os autores, trata-se de uma importante estratégia para aprimorar o conhecimento sobre a forma como se estrutura o programa, assim como seus resultados práticos.

Desse modo, observam-se, dos conceitos apresentados, diferenças entre essas ferramentas. Cohen e Franco (2004) destacam que, enquanto o monitoramento é uma atividade interna da gerência que se realiza durante um período da execução, a avaliação pode ser realizada em qualquer momento: antes, durante ou mesmo 
algum tempo após a implementação de um projeto.

Não obstante as diferenças abordadas, Kusek e Rist (2004) identificam complementaridades entre os processos de monitoramento e de avaliação. De acordo com eles, a primeira é sequencial, isto é, um processo levanta questões ou gera informações que serão respondidas ou irão subsidiar as análises do outro, de forma cíclica. A segunda é de informação, em que os dois processos podem utilizar os mesmos dados, mas realizam análises distintas. Por fim, a terceira é de interação, em que gestores utilizam os dois processos de forma articulada a fim de direcionar suas ações.

Dispor de um sistema regular de informações é fator predominante para a eficiente alocação de recursos e serviços prestados à população, de forma eficaz e com qualidade, e cria bases sustentáveis para a tomada de decisões. Tais informações são elementos de estudo e atuam como subsídios para as atividades de planejamento público e formulação de políticas.

A informação atualizada é ferramenta essencial para a formulação e implemen- tação de políticas públicas. É um dos componentes centrais de qualquer metodologia de monitoramento e avalição de políticas públicas, na medida em que subsidia o diagnóstico da realidade sobre a qual essas políticas atuam e a avaliação das prioridades contidas nas intervenções públicas. É necessário conhecer a real capacidade instalada e a efetiva oferta de serviços por parte de estados e municípios, a fim de identificar necessidades, planejar investimentos, avaliar o desempenho das estruturas instaladas e regular os serviços prestados.

A Pesquisa de Informações Básicas Municipais e a Pesquisa de Informações Básicas Estaduais permitem construir indicadores que possibilitam retratar o grau de participação e controle popular da ação pública, além de caracterizar o estágio de desenvolvimento institucional das atividades de planejamento e gestão municipal, estadual e distrital de diversas políticas públicas pelo país.

Essa informação tem sido ferramenta essencial para a formulação e implementação de políticas públicas, com impacto nas ações dos gestores municipais, estaduais e federais. 
A Secretaria Especial dos Direitos Humanos da Presidência da República (SEDH/ PR), órgão do Governo Federal responsável pela articulação e implementação das políticas de promoção e proteção dos direitos humanos, para o desenvolvimento de suas atribuições necessita de informações atualizadas sobre o desenho institucional dos vários programas, ações e serviços públicos oferecidos nos municípios e estados, no intuito de melhorar o planejamento deste trabalho.

A MUNIC e a ESTADIC demonstraram ser as melhores ferramentas para auxiliar no diagnóstico, monitoramento e avaliação das políticas, programas e estruturas administrativas disponíveis nos municípios e unidades da federação para a proteção, defesa e promoção dos direitos humanos. Essa parceria foi essencial para compreender como os municípios e unidades da federação organizam os órgãos gestores de direitos humanos e quais medidas administrativas e legislativas desenvolvem para promover e garantir esses direitos, tanto em sua universalidade quanto na proteção a grupos de particular vulnerabilidade, como crianças e adolescentes; idosos; pessoas com deficiência; e lésbicas, gays, bissexuais, travestis e transexuais.
A abrangência das pesquisas e a inserção de questões específicas ou transversais de direitos humanos potencializarão ainda mais a capacidade de contribuir com a orientação de diversas políticas públicas dos vários órgãos do governo federal.

A Secretaria Especial de Políticas para as Mulheres (SPM), que estabelece políticas públicas que contribuem para a melhoria da vida de todas as brasileiras, reafirmando o compromisso do Governo Federal com as mulheres do país, utiliza as pesquisas para conhecer a existência e a distribuição espacial dos organismos governamentais voltados ao atendimento de mulheres. Desta forma, está aprimorando o desenvolvimento das políticas para mutheres de acordo com as diferentes realidades locais, otimizando recursos e esforços e tornando efetiva a ideia de um pacto federativo. As experiências de organismos executivos ou de serviços governamentais de atendimento às mulheres são bastante recentes e pouco documentadas. Assim, torna-se mais importante realizar este diagnóstico, que permite não apenas conhecer a realidade dos municípios e unidades da federação nesta área, mas também aprimorar e monitorar a política implementada pelo governo federal. 
O Ministério do Desenvolvimento Social e Combate à Fome, órgão responsável por promover o desenvolvimento social e combater a fome visando à inclusão e a promoção da cidadania, garantindo a segurança alimentar e nutricional, uma renda mínima de cidadania e assistência integral às famílias, vem utilizando a MUNIC e a ESTADIC para mapear a estrutura dos serviços públicos municipais de Assistência Social, produzindo dados e informações referentes às seguintes dimensões: estrutura organizacional do órgão gestor da Assistência Social; legislação e instrumentos de gestão da Assistência Social em âmbito municipal; estrutura e funcionamento dos Conselhos Municipais de Assistência Social; recursos humanos e financeiros vinculados ao órgão gestor da Assistência Social; tipos de serviços prestados pela rede municipal de Assistência Social; dimensão e capacidade de atendimento da rede municipal de Assistência Social.

No âmbito da consolidação da nova política de Assistência Social, o desenvolvimento de um Sistema Nacional de Informações da Assistência Social é fundamental para o aprimoramento da gestão, além de institucionalizar práticas de monitora- mento e avaliação do conjunto de ações, programas, serviços e benefícios da política assistencial. O desenvolvimento deste sistema pressupõe o conhecimento e a capacidade institucional e técnica das secretarias municipais, estaduais, distrital, e das instâncias de controle social operando localmente.

A política pública que consegue alcançar seus objetivos, conhecer de fato seu público alvo e proporcionar melhorias nas condições de vida das pessoas beneficiadas pelo programa, ação ou projeto que está sendo monitorado e avaliado é, de fato, uma política pública efetiva e eficaz.

\section{Conclusão}

O monitoramento e a avaliação tem sido definidos como instrumento imprescindível para o conhecimento da viabilidade de programas, ações ou projetos, para o redirecionamento de seus objetivos, quando necessário, ou mesmo para a reformulação de suas propostas e atividades. A política pública que consegue alcançar seus objetivos, conhecer de fato seu público alvo e proporcionar melhorias nas condições de vida das pessoas beneficiadas 
pelo programa, ação ou projeto que está sendo monitorado e avaliado é, de fato, uma política pública efetiva e eficaz. Nesse sentido, o monitoramento e a avaliação se revelam como um importante mecanismo de gestão, uma vez que fornecem informações e subsídios para tomada de decisão dos gestores, formuladores e implementadores de programas, possibilitando conhecer o que está acontecendo e atuar sobre os fatos de forma a realizar ajustes necessários, economizando-se tempo e recursos, o que eleva a credibilidade das ações públicas.

A informação é um dos componentes centrais de qualquer metodologia de monitoramento e avaliação de políticas públicas, na medida em que subsidia o diagnóstico da realidade sobre a qual essas políticas atuam e a avaliação das prioridades contidas nas intervenções públicas. Da qualidade e da natureza da informação dependerá a possibilidade de confrontar o quadro de carências com o direcionamento dos investimentos públicos. Nesse sentido, a MUNIC e a ESTADIC tornaram-se ferramentas que contribuem com os processos de monitoramento e avaliação de políticas públicas, por se tratarem de pes- quisas que permitem conhecer a organização e a institucionalização de programas e projetos nas administrações municipais e estaduais. Com a abrangência de temas abordados, se potencializa ainda mais a capacidade de contribuir com a orientação de diversas políticas públicas dos vários órgãos governamentais e a orientação à sociedade civil para a participação na condução das políticas.

Além disso, com a articulação das pesquisas (MUNIC e ESTADIC), e contando também com as informações provenientes da União, podemos fornecer um reconhecimento da federação brasileira, a única no mundo que reconhece as três instâncias, local, regional e nacional, como entes federados.

Isto representa, do ponto de vista dos indicadores de gestão e dos indicadores sociais como um todo, um salto de qualidade na análise da interação institucional, o que auxilia o diagnóstico e a avaliação deste processo ainda recente no país. Trata-se de um conhecimento indispensável para a promoção do desenvolvimento, da democracia e da qualidade da gestão no Brasil. 